\title{
Effect of arterial oxygen partial pressure inflection point on Venoarterial extracorporeal membrane oxygenation for emergency cardiac support
}

\author{
Hao Zhou ${ }^{\dagger}$, Yi Zhu ${ }^{\dagger}$, Zhongman Zhang, Jinru Lv, Wei Li, Deliang Hu, Xufeng Chen ${ }^{*}$ and Yong Mei
}

\begin{abstract}
Background: Temporary circulatory support is a bridge between acute circulatory failure and definitive treatment or recovery. Currently, venoarterial extracorporeal membrane oxygenation (VA-ECMO) is considered to be one of the effective circulatory support methods, although cardiac function monitoring during the treatment still needs further investigation. Inflection point of arterial oxygen partial pressure (IPPaO2) may occur at an early stage in part of patients with a good prognosis after VA-ECMO treatment, and the relationship between time of IPPaO2 (tIPPaO2) and recovery of cardiac function or prognosis remains unclear.
\end{abstract}

Methods: To investigate this relationship, we retrospectively analyzed the clinical data of 71 patients with different conditions after treatment with VA-ECMO in the emergency center of Jiangsu Province Hospital between May 2015 and July 2020. Spearman's correlation analysis was used for the correlation between $\mathrm{tIPaO}_{2}$ and quantitative data, and $\mathrm{ROC}$ curve for the predictive effect of $\mathrm{tIPaO}_{2}$ on the 28-day mortality.

Results: Thirty-five patients were admitted because of refractory cardiogenic shock (26 of 35 survived) and the remaining 36 patients due to cardiac arrest (13 of 36 survived). The overall survival rate was $54.9 \%$ (39 of 71 survived). Acute physiology and chronic health evaluation II, ECMO time, tIPPaO2, continuous renal replacement therapy time, mechanical ventilation time, and bleeding complications in the survival group were lower than those in the non-survival group, with length of stay, intensive care unit stay, and platelet levels were being higher. The $\mathrm{tIPPaO}$ was negatively correlated with ejection fraction, and the shorter tIPPaO2 resulted in a higher 28-day survival probability, higher predictive value for acute myocardial infarction and fulminant myocarditis.

Conclusions: Therefore, tIPPaO2 could be a reliable qualitative indicator of cardiac function in patients treated with VA-ECMO, which can reveal appropriate timing for adjusting VA-ECMO flow or weaning.

Trial registration: ChiCTR1900026105.

Keywords: $\mathrm{VA}-\mathrm{ECMO}, \mathrm{tPPaO}_{2}$, Refractory cardiogenic shock, Cardiac arrest, Cardiac function

\footnotetext{
*Correspondence: njmumy11@163.com; njmumy11@163.com

${ }^{+}$Hao Zhou and Yi Zhu contributed equally to this work.

Emergency Department, Jiangsu Province Hospital and Nanjing Medical

University First Affiliated Hospital, Nanjing 210029, China
}

(c) The Author(s). 2021 Open Access This article is licensed under a Creative Commons Attribution 4.0 International License, which permits use, sharing, adaptation, distribution and reproduction in any medium or format, as long as you give appropriate credit to the original author(s) and the source, provide a link to the Creative Commons licence, and indicate if changes were made. The images or other third party material in this article are included in the article's Creative Commons licence, unless indicated otherwise in a credit line to the material. If material is not included in the article's Creative Commons licence and your intended use is not permitted by statutory regulation or exceeds the permitted use, you will need to obtain permission directly from the copyright holder. To view a copy of this licence, visit http://creativecommons.org/licenses/by/4.0/ The Creative Commons Public Domain Dedication waiver (http://creativecommons.org/publicdomain/zero/1.0/) applies to the data made available in this article, unless otherwise stated in a credit line to the data. 


\section{Introduction}

Acute circulatory failure (ACF) is a commonly occurring acute severe syndrome in the emergency department. Multiple causes, including myocardial infarction (AMI), fulminant myocarditis (FMC), sepsis-associated cardiomyopathy (SACM), and cardiotoxic drug poisoning, can lead to ACF, which is often manifested as refractory cardiogenic shock (RCS) or even cardiac arrest (CA) $[1,2]$. In the last decade, venoarterial extracorporeal membrane oxygenation (VA-ECMO) has been increasingly used for the salvage treatment of ACF because it can be percutaneously performed quickly at bedside, thereby rapidly providing oxygenated blood with a stable flow rate for cardiopulmonary replacement until definitive treatment or recovery of cardiac function [1-5].

However, due to lack of randomized controlled trial (RCT), many problems associated with VA-ECMO still need further exploration, such as monitoring of cardiac function during treatment and overall prognosis $[1,5]$. The oxygenated blood flow pumped by peripheral VAECMO is mostly opposite to that pumped by the heart. The higher reversed blood flow rate may generate a series of hemodynamic changes to delay recovery of cardiac function [5]. Therefore, it is essential to closely monitor cardiac function and timely adjust VA-ECMO blood flow according to the state of cardiac function.

The area where VA-ECMO retrograde blood flow mixes with antegrade blood flow pumped by the heart is called a "watershed" $[5,6]$. In our experience, it has been found that the "watershed" is located in the front of the opening of the brachiocephalic trunk when the cardiac function is poor, while arterial oxygen partial pressure $\left(\mathrm{PaO}_{2}\right)$ measured using the right upper brachial artery catheterization is dominated by the ECMO flow. At this time the $\mathrm{PaO}_{2}$ can reach the level of $300 \mathrm{mmHg}$ (Fig. 1a). As the cardiac function gradually improves, the selfpumping blood flow rate increases and the "watershed" moves to the distally of the brachiocephalic trunk opening. The $\mathrm{PaO}_{2}$ is mainly the cardiac blood flow when $\mathrm{PaO}_{2}$ is low at about $100 \mathrm{mmHg}$ (Fig. 1b). Therefore, a sudden decrease in $\mathrm{PaO}_{2}$ in the right upper arm and the occurrence of the "inflection point" change may be closely related to cardiac function. The primary objective of this retrospective study was to determine the

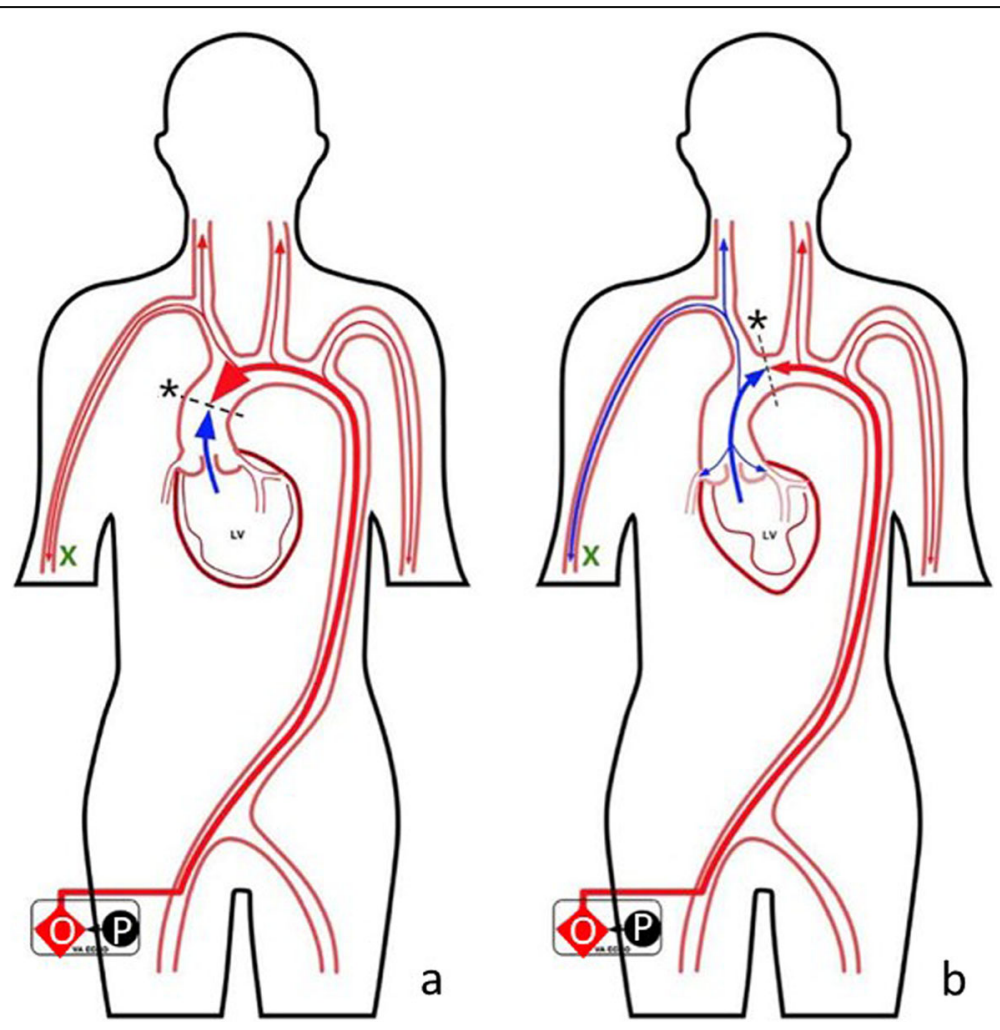

Fig. 1 Schematic diagram of the retrograde blood flow from VA-ECMO against the antegrade blood flow pumped by the heart. Legend: The red diamond stands for the ECMO oxygenator, LV for the left ventricle, red vessels for arteries, red lines and arrows for the direction of ECMO oxygenated blood flow, and the blue lines and arrows for the direction of the pumping blood flow from the heart. The black dotted line represents the intersection plane of blood flow, and the black * indicates the $\mathrm{PPaO}_{2}$. The intersection plane is located in the front of the opening of the brachiocephalic trunk when the cardiac function is poor (a); When the cardiac function gradually improves, the self-pumping blood flow rate increases, and the intersection plane moves to the distal part of the brachiocephalic trunk opening (b). 
association between time of inflection point of $\mathrm{PaO} 2$ (tIPPaO2) and cardiac function in patients with different diseases. In addition, we also sought to evaluate the association between $\mathrm{tIPPaO} 2$ and overall prognosis.

\section{Materials and methods Study design}

The study was approved by the Ethics Committee of the First Affiliated Hospital of Nanjing Medical University (Jiangsu Province Hospital). Informed consent was signed by legal representatives of all patients before catheterization. Clinical data of 92 patients diagnosed with ACF requiring VA-ECMO support treatment at the emergency center of the hospital between May 2015 and July 2020 were retrospectively analyzed. The data included patient characteristics, diagnosis and supportive ACF treatment, treatment monitoring, and prognosis (28-day survival rate, intensive care unit (ICU) stay, length of stay, continuous renal replacement therapy (CRRT) time, and ejection fraction (EF) value at discharge).

\section{Patient selection}

Inclusion criteria: patients treated with VA-ECMO for CA or RCS with a treatment duration of $\geq 72 \mathrm{~h}$. CA initiation criteria: 1) in-hospital cardiac arrest; 2) out-ofhospital cardiac arrest with witnesses and effective cardiopulmonary resuscitation (CPR) within $10 \mathrm{~min}$; 3) age of $\leq 65$ years; 4) suspected reversible causes; and 5) CPR time before initiation of $\leq 60 \mathrm{~min}$ [7]. RCS initiation criteria: 1) persistent hypotension after traditional treatment, including full fluid resuscitation and high dose vasopressors; 2) blood lactate ( $\geq 4 \mathrm{mmol} / \mathrm{L}) ; 3$ ) evidence of organ hypoperfusion; and 4) bedside echocardiography suggesting ventricular ejection dysfunction. Exclusion criteria: 1) past cardiac disease affected cardiac EF; 2) post-cardiac surgery; 3) mode conversion during ECMO; 4) treatment time of $\leq 72 \mathrm{~h}$; and 5) VA-ECMO with non-femoral artery-vein catheterization $[4,8]$.

\section{Supportive treatment}

Supportive treatment: 1) ECMO: all patients were in the peripheral VA mode of femoral artery-vein catheterization, and the initial blood flow maintained mean arterial pressure at $65 \mathrm{mmHg}$; the ratio of air flow to blood flow was 1:1 with an oxygen concentration of $100 \%$, which then increased or decreased according to the arterial blood gas analysis result; 2) mechanical ventilation (MV): mechanical ventilation after endotracheal intubation with synchronous intermittent mandatory ventilation, tidal volume of $8-10 \mathrm{~mL} / \mathrm{kg}$, respiratory rate of 12-20 times/min, inhaled oxygen concentration of $40-60 \%$, and positive end-expiratory pressure of 5-10 $\mathrm{cmH}_{2} \mathrm{O}$; and 3) continuous renal replacement therapy
(CRRT): renal function monitoring, and CRRT treatment if continuous oliguria (urine volume $<0.5 \mathrm{~mL} /(\mathrm{kg} \cdot \mathrm{h})$ ), severe electrolyte disturbance, or progressive elevation of creatinine and urea nitrogen occurred.

\section{Treatment monitoring}

Treatment monitoring was performed using catheterization of the right radial or brachial artery, arterial blood pressure monitoring, observing pulse pressure difference and arterial waveform in real-time, analyzing arterial blood gas and activated clotting time (ACT) every 4-6h (Fig. 1, green fork represents monitoring point), and performing bedside cardiac ultrasound every $24 \mathrm{~h}$. If the pulse pressure difference suddenly became large or the amplitude of the arterial waveform suddenly increased, blood gas analysis was performed immediately $[9,10]$. If there was an inflection point change in $\mathrm{PaO}_{2}, \mathrm{tIPPO}_{2}$ was recorded and bedside cardiac ultrasound was performed immediately.

\section{Statistical analysis}

SPSS 24.0 (IBM Corp., Armonk, NY, USA) was used for statistical analysis. Quantitative data meeting normal distribution were expressed as mean \pm standard deviation. Independent sample t-test was used to compare the differences between groups. Median (quartile) was used to describe the distribution of quantitative data with a nonnormal distribution. Mann Whitney $U$ test was used to compare the differences between groups. Frequency and constituent ratio were used to describe the distribution of qualitative data. Chi square test or Fisher's exact probability method was used to compare the differences between groups. Spearman's correlation analysis was done for the correlation between $\mathrm{tIPPO}_{2}$ and quantitative data, while ROC curve was used to analyze the predictive effect of $\mathrm{tIPaO}_{2}$ on the 28 -day mortality. $P$ value of $<0.05$ was regarded as statistically significant.

\section{Results}

\section{Patient characteristics}

We collected the clinical data of 92 patients, of which 21 were excluded because their ECMO support time was $\leq 72 \mathrm{~h}(n=9)$, mode changed from VA to VAV during $\operatorname{ECMO}(n=3)$, data were incomplete $(n=7)$, and past cardiac disease affected EF $(n=2)$. A total of 71 patients were included in the final statistical analysis (Fig. 2). Totally 39 of the 71 patients (54.9\%) survived, of which 35 were treated with VA-ECMO for RSC (26 survivors of 35 patients) and the remaining 36 were treated with $C A$ (13 survivors of 36 patients). The most common primary disease was FMC (24 survivors of 31 patients), followed by AMI (10 survivors of 22 patients), SACM ( 2 survivors of 5 patients), and other causes related cardiac arrest (OCCA, 3 survivors of 13 patients), including two 


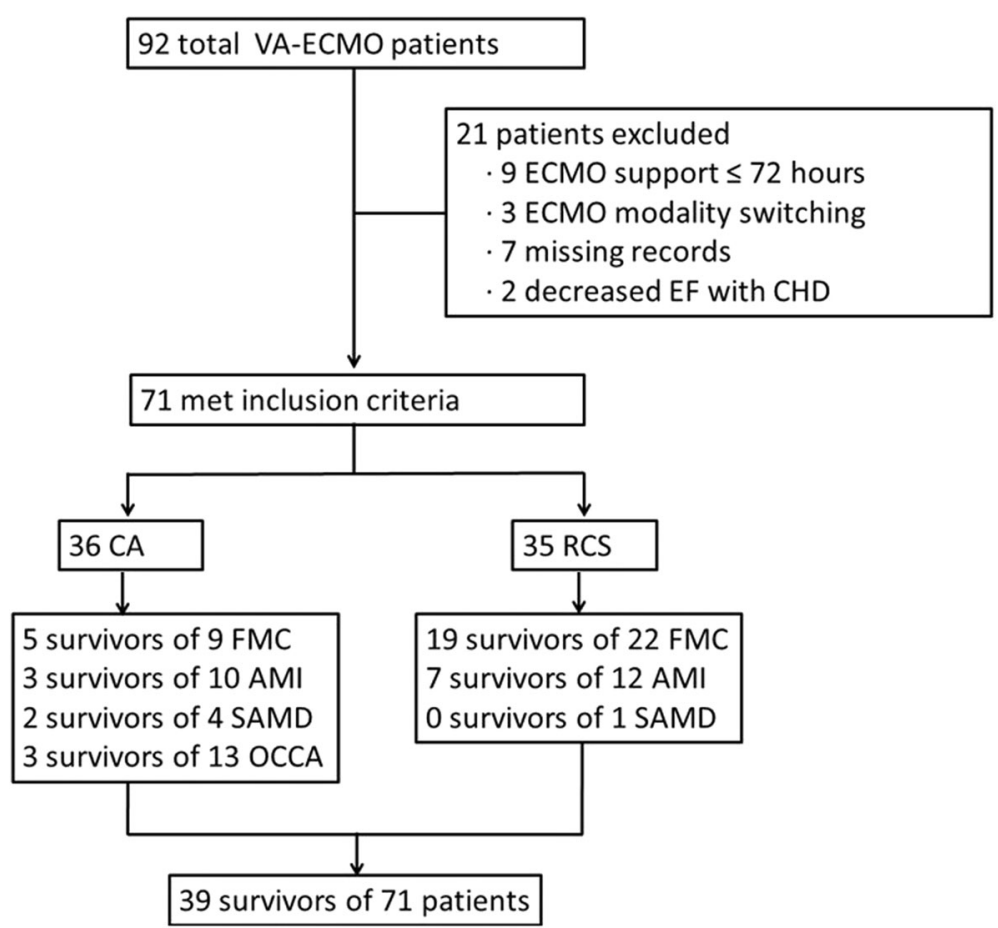

Fig. 2 Summary of treatment for CA and RCS patients with VA-ECMO. Legend: VA-ECMO, venoarterial extracorporeal membrane oxygenation; CHD: chronic cardiac dysfunction; RSC, refractory cardiogenic shock; CA, cardiac arrest; EF, ejection fraction; AMI, acute myocardial infarction; FMC, fulminant myocarditis; SACM, sepsis-associated cardiomyopathy; OCCA, other causes related cardiac arrest

patients with trauma-related cardiac arrest (1 survivors of 2 patients), three with pulmonary embolism ( 2 survivors of 3 patients), four with poisoning-associated myocardial depression, one with hyperthyroidism, one with ketoacidosis, one with severe electrolyte disorder, and one with CA during puerperium.

The average participant age was $44.8 \pm 16.7$ years and $63.4 \%$ of the patients were male $(n=45)$. There were no significant differences in age, sex, body mass index (BMI), comorbidities (hypertension, diabetes, past definite history of coronary heart disease, history of arrhythmia, chronic lung disease, autoimmune diseases, and tumors), history of tobacco and alcohol use, or catheter-related blood-borne infections between the survival and non-survival groups. The median acute physiology and chronic health evaluation (APACHE) II score in the survival group was significantly lower than that in the non-survival group (24.0 vs. 34.5$)$. The ECMO support time $(131.0$ vs. $168.5 \mathrm{~h}), \mathrm{tIPPaO}_{2}(30.0$ vs. $92.0 \mathrm{~h})$, CRRT time (0.0 vs. $6.0 \mathrm{~h})$, and MV time (7.0 vs. $9.0 \mathrm{~h}$ ) were significantly lower in the survival group than in the non-survival group, while the length of stay (20.0 vs. $9.0 \mathrm{~d})$ and ICU stay (17.0 vs. $9.0 \mathrm{~d}$ ) were significantly longer than those in the non-survival group. The minimum platelet count in the survival group was significantly higher than that in the non-survival group (69.5 vs. $31.0^{*} 10^{\wedge} 9 / \mathrm{L}$ ), while bleeding complications were less than those in the non-survival group ( 3 vs. 16 cases; Table 1).

\section{Predicting 28-day mortality using $\mathrm{tIPPaO}_{2}$}

Mann-Whitney U test analysis showed that $\mathrm{IIPaO}_{2}$ was significantly shorter in the survival group than that in the non-survival group. The ROC curve demonstrated that as the $\mathrm{tPPaO}_{2}$ decreased the 28-day survival probability increased. The cut-off value was set at $62 \mathrm{~h}$, prediction sensitivity was $92.3 \%$, and specificity was $65.6 \%$ (Fig. 3). The ROC curve constructed for different diseases (FMC, AMI, SACM, and OCCA) identified that the $\mathrm{tIPaO}_{2}$ cut-off value for FMC was $68 \mathrm{~h}$, with the best sensitivity and specificity of 100 and $85.7 \%$, respectively. This was followed by the $\mathrm{tIPaO}_{2}$ cut-off value of $83.5 \mathrm{~h}$ for AMI, with sensitivity and specificity of 100 and $50.0 \%$, respectively. The $\mathrm{tPPaO}_{2}$ had no predictive value for SACM and OCCA (Table 2).

\section{Correlation between $\mathrm{tIPPaO} 2$ and $\mathrm{EF}$ value, invasive treatment time, and relevant laboratory tests}

Spearman's correlation analysis was used to study the correlation between $\mathrm{tIPPaO}_{2}$ and recent EF value, longterm $\mathrm{EF}$ value, invasive treatment time, and relevant laboratory tests. It was found that $\mathrm{IPPaO}_{2}$ was negatively correlated with post-inflection EF, pre-discharge EF, ICU stay, length of stay, and PLT. It was positively correlated 
Table 1 Baseline characteristics of patients on VA-ECMO for ACF

\begin{tabular}{|c|c|c|c|}
\hline & Survivor & No- Survivor & $p$-value \\
\hline Age & $43.9 \pm 16.7$ & $45.8 \pm 16.8$ & 0.638 \\
\hline $\operatorname{Sex}(M: F)$ & $22 / 17$ & $23 / 9$ & 0.220 \\
\hline BMl & $23.1 \pm 3.4$ & $24.1 \pm 3.5$ & 0.227 \\
\hline \multicolumn{4}{|l|}{ Comorbidities, n (\%) } \\
\hline Coronary artery disease & $1(2.6)$ & $1(3.1)$ & $>0.999$ \\
\hline Hypertension & $5(12.8)$ & $8(25.0)$ & 0.227 \\
\hline Diabetes Mellitus & $3(7.7)$ & $7(21.9)$ & 0.168 \\
\hline Lung disease & $1(2.6)$ & $2(6.3)$ & 0.585 \\
\hline Previous Arrhythmia & $0(0.00)$ & $2(6.3)$ & 0.200 \\
\hline Tumour & $3(7.7)$ & $2(6.3)$ & $>0.999$ \\
\hline Autoimmune disease & $3(7.7)$ & $0(0.00)$ & 0.247 \\
\hline Smoking & $10(25.6)$ & $11(34.4)$ & 0.446 \\
\hline Alcohol & $9(23.1)$ & $5(15.6)$ & 0.553 \\
\hline APACHE ॥ & $24.0[19.0,31.5]$ & $34.50[28.3,36.0]$ & 0.002 \\
\hline Protopathy & & & 0.003 \\
\hline FMC & $24(61.5)$ & $7(21.9)$ & \\
\hline AMI & $10(25.6)$ & $12(37.5)$ & \\
\hline SACM & $2(5.1)$ & $3(9.4)$ & \\
\hline OCCA & $3(7.7)$ & $10(31.3)$ & \\
\hline Reason of ECMO & & & 0.002 \\
\hline RSC & $26(66.7)$ & $9(28.1)$ & \\
\hline CA & $13(33.3)$ & $23(71.9)$ & \\
\hline \multicolumn{4}{|l|}{ Complications } \\
\hline Bleeding & $3(7.7)$ & $16(50.0)$ & $<0.001$ \\
\hline CRBSI & $0(0.0)$ & $3(9.4)$ & 0.087 \\
\hline ECMO support time & $131.0[116.0,178.0]$ & $168.5[124.3,219.3]$ & 0.047 \\
\hline $\mathrm{tIPPaO} 2$ & $30.0[17.5,50.0]$ & $92.00[48.8,148.5]$ & $<0.001$ \\
\hline ICU time & $17.0[15.0,24.5]$ & $9.0[7.0,13.3]$ & $<0.001$ \\
\hline length of stay & $20.0[17.5,30.0]$ & $9.00[7.0,13.3]$ & $<0.001$ \\
\hline CRRT time & $0.0[0.0,5.0]$ & $6.0[3.0,8.3]$ & 0.001 \\
\hline MV time & $7.0[5.0,9.0]$ & $9.00[7.0,12.3]$ & 0.022 \\
\hline Platelet & $69.5[50.3,93.0]$ & $31.0[22.8,42.3]$ & $<0.001$ \\
\hline
\end{tabular}

$B M I$ body mass index, $A P A C H E$ acute physiology and chronic health evaluation, $F M C$ fulminant myocarditis, $A M I$ acute myocardial infarction, SACM sepsisassociated cardiomyopathy, OCCA other causes related cardiac arrest, RSC refractory cardiogenic shock, CA cardiac arrest, CRBSI catheter-related blood stream infection, $t I P P a O 2$ time of inflection point of arterial oxygen partial pressure, ICU intensive care unit, CRRT continuous renal replacement therapy and $M V$ mechanical ventilation

with CRRT treatment time. The $\mathrm{IPPaO}_{2}$ had no correlation with peak TnT, peak BNP, duration of ECMO support time and time of MV (Table 3).

The correlation analysis between the $\mathrm{IPPaO}_{2}$ and recent EF in different diseases showed that $\mathrm{IPPaO}_{2}$ was significantly negatively correlated with recent EF in patients with FMC and AMI. There was no correlation between $\mathrm{IPPaO}_{2}$ and recent EF in patients with SACM and OCCA (Table 4).

\section{Discussion}

VA-ECMO arterial blood flow is reversed compared to the cardiac pump blood flow. High level of retrograde blood flow may enhance cardiac afterload, increase myocardial work, and affect cardiac recovery. Increased afterload can also lead to elevated left ventricular enddiastolic pressure, possibly worsening pulmonary edema [5]. Therefore, timely monitoring of cardiac function and adjustment of VA-ECMO flow are essential for the recovery of cardiac function in ACF patients. It has been 


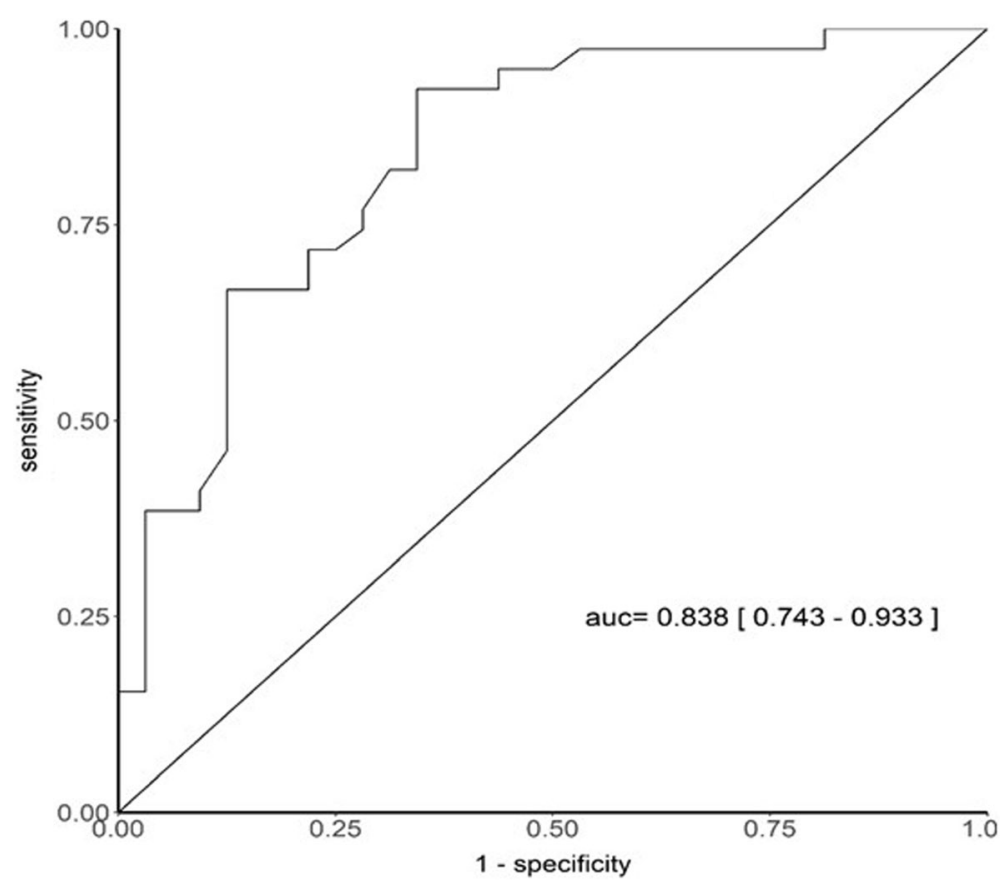

Fig. 3 The ROC curve to predict 28-day mortality using tIPPaO2. Legend: The cut-off value was set at $62 \mathrm{~h}$, prediction sensitivity was $92.3 \%$, and specificity was $65.6 \%$. tIPPaO2, time of inflection point of arterial oxygen partial pressure

reported that the location of the "watershed" is closely related to the cardiac function, which can indirectly reflect the balance between cardiac function and VAECMO retrograde flow. Aortic computed tomography angiography and aortic contrast-enhanced ultrasound can accurately reflect the location of the "watershed", although it is difficult to realize real-time monitoring [9]. The present study found that an abrupt decrease in $\mathrm{PaO}_{2}$ (inflection point) monitored using right radial/ right brachial artery catheterization can indicate that the "watershed" moved from the proximal end of the brachiocephalic trunk to the distal end, representing a "trigger" improvement of cardiac function. This phenomenon can further evaluate cardiac function and adjust ECMO flow in a timely fashion. Our retrospective study showed that $\mathrm{IPPaO}_{2}$ is negatively correlated with patient EF and the 28-day mortality. Because VA-ECMO needs $4-6 \mathrm{~h}$ to routinely monitor arterial blood gas and can be performed at any time according to the changes in arterial waveform and pulse pressure difference when needed, it is a simple, easy, and cheap method with a high monitoring sensitivity and compliance. In conclusion, we believe that $\mathrm{IIPaO}_{2}$ could be a good qualitative indicator for monitoring cardiac function in patients treated with VA-ECMO, which can reveal appropriate timing for adjusting VA-ECMO flow or weaning.

CA and RCS are common critical illnesses with extremely low overall survival. Reportedly, traditional CPR therapy survival rate for in-hospital CA is between 35.6 and $39.7 \%$ and between 7.7 and $8.3 \%$ for out-of-hospital CA $[7,11]$. RCS mortality rate is also high at $30-60 \%$ [10] Multi-center prospective RCT studies are still lacking because multiple factors affect the VA-ECMO treatment prognosis and complex ethical issues are involved in the process. However, a few studies, such as ARREST trial [12], show that CA/RCS patients treated with VAECMO might improve survival compared with traditional treatment $[5,7,11,13]$. Therefore, VA-ECMO is

Table 2 Predicting 28-day mortality using tIPPaO2 for different diseases

\begin{tabular}{lllllll}
\hline & Group & AUC & P & Cutoff & Sensitivity & Specificity \\
\hline Protopathy & FMC & $0.92(0.786-1.000)$ & $<0.001$ & 68.0 & 100.0 & 85.7 \\
& AMI & $0.767(0.561-0.972)$ & 0.011 & 83.5 & 100.0 & 50.0 \\
& SACM & $0.667(0.000-1.000)$ & 0.655 & 76.0 & 50.0 & 66.7 \\
& OCCA & $0.633(0.089-1.000)$ & 0.631 & 37.0 & 66.7 & 90.0 \\
\hline
\end{tabular}

FMC fulminant myocarditis, $A M I$ acute myocardial infarction, SACM sepsis-associated cardiomyopathy and OCCA other causes related cardiac arrest 
Table 3 Correlation between tIPPaO2 and EF value, invasive treatment time, and relevant laboratory tests

\begin{tabular}{lll}
\hline Factors & tIPPaO2 & \\
\cline { 2 - 3 } & $\mathbf{r}$ & $\mathbf{P}$ \\
\hline Post-inflection EF & -0.528 & 0.000 \\
Pre-discharge EF & -0.546 & 0.000 \\
ICU stay & -0.404 & 0.003 \\
Length of stay & -0.426 & 0.001 \\
Time of ECMO & 0.208 & 0.327 \\
Time of MV & 0.199 & 0.327 \\
Time of CRRT & 0.319 & 0.033 \\
Platelet & -0.457 & 0.001 \\
Peak TnT & 0.142 & 0.474 \\
Peak BNP & 0.025 & 0.835
\end{tabular}

$E F$ ejection fraction, ICU intensive care unit, CRRT continuous renal replacement therapy, $M V$ mechanical ventilation, $T n T$ Troponin T and $B N P$ brain natriuretic peptide

cautiously recommended as an alternative option for CA/RCS $[1,4,10,14]$. The present study showed an overall survival rate similar to that in previous studies $[10,12,15]$. VA-ECMO prognosis and initiation timing for the treatment of ACF have been reported to be closely related. If the time from CA to initiation of VAECMO is $<30 \mathrm{~min}$, the survival rate can be $50 \%$, which is reduced to $30 \%$ at $30-60 \mathrm{~min}[7,16,17]$. The best time for VA-ECMO support in RCS patients is before irreversible multi-organ dysfunction occurs $[10,18]$. The unified criteria for the timing of initiation are currently lacking. The time from CPR to ECMO initiation in our center is $\leq 60 \mathrm{~min}$. The RCS initiation criterion states that the dosage of vasopressor drugs continues to increase after active fluid resuscitation of $>6 \mathrm{~h}$. Blood $\mathrm{pH}$ still progressively decreases, while lactate progressively increases, accompanied by obvious evidence of organ hypoperfusion. Whether these timings are optimal remains unclear, but we believe that if ECMO treatment is necessary after careful evaluation by a professional team, early initiation of ECMO is beneficial for the prognosis of CA/RCS patients.

VA-ECMO can be used as a bridge therapy for cardiac function recovery or definite treatment $[1,4,5]$.. FMC is a self-limiting disease. The cardiac function can be

Table 4 Correlation between the tIPPaO2 and Post-inflection EF in different diseases

\begin{tabular}{lll}
\hline Protopathy & $\mathbf{r}$ & $\mathbf{P}$ \\
\hline FMC & -0.541 & 0.002 \\
AMI & -0.487 & 0.021 \\
SACM & -0.100 & 0.873 \\
OCCA & -0.247 & 0.415 \\
\hline
\end{tabular}

FMC fulminant myocarditis, $A M I$ acute myocardial infarction, $S A C M$ sepsisassociated cardiomyopathy and OCCA other causesrelated cardiac arrest gradually recovered after the outbreak period [19]. Percutaneous coronary intervention can effectively recanalize the AMI culprit vessels, providing conditions for cardiac function recovery $[10,20]$. . There are fewer studies on myocardial inhibition induced by other factors, where the supportive effect of VA-ECMO remains unclear [1]. The present study also found that $\mathrm{IPPaO}_{2}$ has a high sensitivity for predicting the prognosis of FMC and AMI, but poor sensitivity for SACM and OCCA.

According to a report, the need for CRRT adjuvant therapy in patients treated with VA-ECMO during the first $72 \mathrm{~h}$ is an independent risk factor for increased 90 day mortality [21]. Patients with cardiac pump failure requiring simultaneous support of VA-ECMO and CRRT usually have multiple organ dysfunction, and CRRT can effectively reduce severe fluid overload during VAECMO treatment [22]. A shorter $\mathrm{tIPPaO}_{2}$ means faster recovery of the cardiac function as shown in Table 3. Moreover, early VA-ECMO flow decline can also effectively reduce the high pressure time for CRRT and improve CRRT efficiency. The present study confirmed that CRRT time was significantly shorter in the survival group than in the non-survival group, and that $\mathrm{tIPaO}_{2}$ was positively correlated with CRRT treatment time.

Heparin-induced thrombocytopenia, aggravation of primary disease, and mechanical consumption of VAECMO may all lead to thrombocytopenia. Studies have shown that patients treated with VA-ECMO have a significant requirement for blood transfusion, and those with an extreme need for blood transfusion have an increased mortality rate. However, transfusion-related predictors are lacking [23]. The correlation analysis indicated a negative correlation between $\mathrm{tIPaO}_{2}$ and the platelet count. Thus, platelet destruction might be related to VA-ECMO flow. The specific mechanism and prediction of blood transfusion demand using $\mathrm{tIPPaO}_{2}$ need further experimental verification.

The present study had some limitations. First, the gold standard for assessing the "watershed" is contrastenhanced ultrasound, which can directly identify the "watershed" location, but, on the other hand, is relatively complex. We chose bedside ultrasound as the contrast standard, because many cases of $\mathrm{tIPPO}_{2}$ had occurred late at night and instant bedside ultrasound was more convenient to use. Second, the sample size of VAECMO was small and the occurrence of each individual disease was even lower. The present case comparison mainly focused on FMC and AMI, a small number of SACM, and cases of cardiac arrest caused by other mostly sporadic reasons. Thus, the combined OCCA treatment was chosen for analysis. The in-hospital and out-of-hospital CA was also not distinguished. Finally, this analysis was retrospective as reported in the literature. Strict and uniform randomized control criteria 
were not utilized and many cases of ECMO treatment options and timing were based on the clinician judgment $[7,11]$.

\section{Conclusions}

In conclusion, $\mathrm{tIPPaO} 2$ may be a good qualitative indicator of cardiac function in patients treated with VAECMO that can provide a timely and reliable basis for adjusting VA-ECMO flow. $\mathrm{IPPaO}_{2}$ was negatively correlated with 28-day survival probability, EF, ICU stay, length of hospitalization, and higher predictive value for acute AMI and FMC.

\section{Abbreviations}

ACF: Acute circulatory failure; VA-ECMO: Venoarterial extracorporeal membrane oxygenation; tIPPaO2: time of inflection point of arterial oxygen partial pressure; RSC: Refractory cardiogenic shock; CA: Cardiac arrest; APAC HE: Acute physiology and chronic health evaluation; CRRT: Continuous renal replacement therapy; MV: Mechanical ventilation; ICU: Intensive care unit; EF: Ejection fraction; AMI: Acute myocardial infarction; FMC: Fulminant myocarditis; SACM: Sepsis-associated cardiomyopathy; OCCA: Cardiac arrest caused by other causes; BMl: Body mass index

\section{Supplementary Information}

The online version contains supplementary material available at https://doi. org/10.1186/s13049-021-00902-5.

\section{Additional file 1}

\section{Acknowledgements}

We would like to thank all the staff of the emergency center of the First Affiliated Hospital of Nanjing Medical University (Jiangsu Province Hospital) for their having contributed data. We are also grateful to every member of the ECMO team for their hard work to take care of the patients treated with ECMO in the center.

\section{Authors' contributions}

Hao Zhou and Yi Zhu participated in the design of the study and drafted the manuscript. Zhongman Zhang performed the statistical analysis. Jinru LV, Wei Li, and Deliang Hu participated in patient management, data collection and analysis. XuFeng Chen conceived the study, and provided finanical support. Yong Mei was responsible for the study design, data collection and manuscript revision. All authors read and approved the final manuscript.

\section{Funding}

This work was supported by Six Talent Peaks Project in Jiangsu Province, grant number [WSN-005] and 511 Research Foundation of Jiangsu Province Hospital, grant number [JSPH-511B-2018-9].

\section{Availability of data and materials}

Our datasets are presented in the additional supporting files.

\section{Declarations}

\section{Ethics approval and consent to participate}

The study was approved by the Ethics Committee of the First Affiliated Hospital of Nanjing Medical University (Jiangsu Province Hospital)(No. 2019NT-12). Informed consent was obtained from all patients.

\section{Consent for publication}

All authors Consent for publication.

\section{Competing interests}

All authors declare no conflicts of interest.
Received: 20 January 2021 Accepted: 11 June 2021

Published online: 08 July 2021

\section{References}

1. Pineton de Chambrun M, Bréchot N, Combes A. Venoarterial extracorporeal membrane oxygenation in cardiogenic shock: indications, mode of operation, and current evidence. Curr Opin Crit Care. 2019:25:397-402.

2. McCarthy FH, McDermott KM, Kini V, et al. Trends in U.S. extracorporeal membrane oxygenation use and outcomes: 2002-2012. Semin Thorac Cardiovasc Surg. 2015;27(2):81-8. https://doi.org/10.1053/j.semtcvs.2015.07. 005.

3. de Waha S, Fuernau G, Eitel I, Desch S, Thiele H. Long-term prognosis after extracorporeal life support in refractory cardiogenic shock - results from a real-world cohort. Eurolntervention. 2016;12(3):414. https://doi.org/10.4244/ EIJV12I3A71.

4. Ponikowski P, Voors AA, Anker SD, ESC Scientific Document Group, et al. 2016 ESC Guidelines for the diagnosis and treatment of acute and chronic heart failure: The Task Force for the diagnosis and treatment of acute and chronic heart failure of the European Society of Cardiology (ESC) Developed with the special contribution of the Heart Failure Association (HFA) of the ESC. Eur Heart J. 2016;37:2129-200.

5. Rao P, Khalpey Z, Smith R, Burkhoff D, Kociol RD. Venoarterial extracorporeal membrane oxygenation for cardiogenic shock and cardiac arrest. Circ Heart Fail. 2018:11:e004905.

6. Napp LC, Kühn C, Bauersachs J. ECMO in cardiac arrest and cardiogenic shock. Herz. 2017:42(1):27-44. https://doi.org/10.1007/s00059-016-4523-4.

7. Wibrandt I, Norsted K, Schmidt H, Schierbeck J. Predictors for outcome among cardiac arrest patients: the importance of initial cardiac arrest rhythm versus time to return of spontaneous circulation, a retrospective cohort study. BMC Emerg Med. 2015;15(1):3. https://doi.org/10.1186/s12873015-0028-3

8. Sun T, Guy A, Sidhu A, Finlayson G, Grunau B, Ding L, et al. Veno-arterial extracorporeal membrane oxygenation (VA-ECMO) for emergency cardiac support. J Crit Care. 2018;44:31-8. https://doi.org/10.1016/j.jcrc.2017.10.011.

9. Napp LC, Brehm M, Kühn C, Schäfer A, Bauersachs J. Heart against venoarterial ECMO: competition visualized. Int J Cardiol. 2015;187:164-5. https:// doi.org/10.1016/j.ijcard.2015.03.311.

10. Chioncel O, Collins SP, Ambrosy AP, Pang PS, Radu RI, Antohi EL, et al. Therapeutic advances in the Management of Cardiogenic Shock. Am J Ther. 2019;26(2):e234-47. https://doi.org/10.1097/MJT.0000000000000920.

11. Twohig CJ, Singer B, Grier G, Finney SJ. A systematic literature review and meta-analysis of the effectiveness of extracorporeal-CPR versus conventional-CPR for adult patients in cardiac arrest. J Intensive Care Soc. 2019;20(4):347-57. https://doi.org/10.1177/1751143719832162.

12. Bartos JA, Grunau B, Carlson C, Duval S, Ripeckyj A, Kalra R, et al. Improved survival with extracorporeal cardiopulmonary resuscitation despite progressive metabolic derangement associated with prolonged resuscitation. Circulation. 2020;141(11):877-86. https://doi.org/10.1161/ CIRCULATIONAHA.119.042173.

13. Yannopoulos D, Bartos J, Raveendran G, Walser E, Connett J, Murray TA et al. Advanced reperfusion strategies for patients with out-of-hospital cardiac arrest and refractory ventricular fibrillation (ARREST): a phase 2 single Centre, open-label, randomised controlled trial. Lancet. 2020; 396(10265):1807-16. https://doi.org/10.1016/S0140-6736(20)32338-2.

14. Abrams D, Garan AR, Abdelbary A, International ECMO Network (ECMONet) and The Extracorporeal Life Support Organization (ELSO), et al. Position paper for the organization of ECMO programs for cardiac failure in adults. Intensive Care Med. 2018;44(6):717-29. https://doi.org/10.1007/s00134-018 5064-5.

15. Richardson AS, Schmidt M, Bailey M, Pellegrino VA, Rycus PT, Pilcher DV. ECMO cardio-pulmonary resuscitation (ECPR), trends in survival from an international multicentre cohort study over 12-years. Resuscitation. 2017;112: 34-40. https://doi.org/10.1016/j.resuscitation.2016.12.009.

16. Wengenmayer T, Rombach S, Ramshorn F, Biever P, Bode C, Duerschmied $D$, et al. Influence of low-flow time on survival after extracorporeal cardiopulmonary resuscitation (eCPR). Crit Care. 2017;21(1):157. https://doi org/10.1186/s13054-017-1744-8.

17. Fagnoul D, Combes A, De Backer D. Extracorporeal cardiopulmonary resuscitation. Curr Opin Crit Care. 2014;20(3):259-65. https://doi.org/10.1097/ MCC.0000000000000098. 
18. Keebler ME, Haddad EV, Choi CW, McGrane S, Zalawadiya S, Schlendorf KH, et al. Venoarterial extracorporeal membrane oxygenation in cardiogenic shock. JACC Heart Fail. 2018;6(6):503-16. https://doi.org/10.1016/j.jchf.201 7.11.017.

19. Li S, Xu S, Li C, Ran X, Cui G, He M, et al. A life support-based comprehensive treatment regimen dramatically lowers the in-hospital mortality of patients with fulminant myocarditis: a multiple center study. Sci China Life Sci. 2019;62(3):369-80. https://doi.org/10.1007/s1 1427-018-9501-9.

20. Karami M, den Uil CA, Ouweneel DM, Scholte NTB, Engström AE, Akin S, et al. Mechanical circulatory support in cardiogenic shock from acute myocardial infarction: Impella CP/5.0 versus ECMO. Eur Heart J Acute Cardiovasc Care. 2020;9(2):164-72. https://doi.org/10.1177/204887261 9865891.

21. Schmidt M, Bailey M, Kelly J, Hodgson C, Cooper DJ, Scheinkestel C, et al. Impact of fluid balance on outcome of adult patients treated with extracorporeal membrane oxygenation. Intensive Care Med. 2014;40(9): 1256-66. https://doi.org/10.1007/s00134-014-3360-2.

22. Ostermann M, Connor M Jr, Kashani K. Continuous renal replacement therapy during extracorporeal membrane oxygenation: why, when and how? Curr Opin Crit Care. 2018;24(6):493-503. https://doi.org/10.1097/MCC 0000000000000559 .

23. Guimbretière G, Anselmi A, Roisne A, Lelong B, Corbineau H, Langanay T, et al. Prognostic impact of blood product transfusion in VA and W ECMO. Perfusion. 2019;34(3):246-53. https://doi.org/10.1177/0267659118814690.

\section{Publisher's Note}

Springer Nature remains neutral with regard to jurisdictional claims in published maps and institutional affiliations.

Ready to submit your research? Choose BMC and benefit from:

- fast, convenient online submission

- thorough peer review by experienced researchers in your field

- rapid publication on acceptance

- support for research data, including large and complex data types

- gold Open Access which fosters wider collaboration and increased citations

- maximum visibility for your research: over $100 \mathrm{M}$ website views per year

At $\mathrm{BMC}$, research is always in progress.

Learn more biomedcentral.com/submissions 